\title{
Management Outcome in Patients with Acquired Gynaetresia in Ibadan.
}

Michael A. Okunlola, Adeyemi O. Adekunle and Ayodele O. Arowojolu

Department of Obstetrics \& Gynaecology, University College Hospital, Ibadan, Nigeria.

\begin{abstract}
:
Context: In marriage, great importance is placed on a satisfactory sexual life and child bearing. Whereas companionship is the primary purpose of marriage in many western societies, here in Nigeria procreation is the central issue in marriage. Acquired gynaetresia is commonly associated with infertility in tropical Africa.

Objective: To determine the prevalence of acquired gynaetresia in our gynaecological practice and assess the outcome of its management.
\end{abstract}

Study Design: A retrospective analysis of patients presenting with acquired gynaetresia between January 1984 and December 1998, at the University College Hospital, Ibadan.

Main Outcome Measures: The relative proportion of cases of acquired gynaetresia compared to the total number of the gynaecological cases seen during the study period. The definitive treatment modalities employed, treatment outcome and the complications encountered.

Result: Acquired gynaetresia accounted for $0.52 \%$ of all major gynaecological admissions during the study period. The patients' ages ranged from 5 to 54 years. Chemical vaginitis from pessary insertion into the vagina was the commonest aetiological factor, followed by complications of female genital mutilation. The 2-stage vaginoplasty (Mcindoe's Operation) was the most commonly employed procedure to restore vaginal patency. Post-operative morbidity was low. Pregnancy was recorded in 5 patients during the follow-up period.

Conclusion: Acquired gynaetresia contributes significantly to reproductive health morbidity in the developing world, often resulting from ignorance and harmful traditional practices. Public health education and wide spread enlightenment of the populace to eliminate the preventable causes is suggested, to reduce the burden of acquired gynaetresia in contemporary gynaecological practice.

Key Words: Acquired Gynaetresia; Treatment Outcome; Vaginoplasty. [Trop J Obstet Gynaecol, 2001, 18: 12-15]

\section{Introduction}

Acquired stenosis of the vagina is much less common than the congenital type in the developed world but the converse is the case in the tropics. In the developed countries; when gynaetresia occurs, it is often iatrogenic, usually following vaginal surgical procedures such as colporraphy and hysterectomy, or sequel to intra-vaginal irradiation in the treatment of gynaecological malignancies'. In the tropics, acquired gynaetresia is a common problem due to some cultural practices, poverty and ignorance ${ }^{2}$. Notable among these are vaginal insertion of local herbs in the treatment of a wide range of gynaecological conditions especially infertility and amenorrhoea. This results in chemical vaginitis and scarring. Other causes are female genital mutilation (often referred to as 'circumcision'), and vaginal stenosis following prolonged obstructed labour.

In many parts of the developed world, vaginoplasty and vulvo-vaginoplasty are operations that are usually carried out on patients with congenital absence of the vagina (a condition reported to occur in one out of every 500 births), whereas at Ibadan, vaginoplasty is an operation that is performed more frequently on patients with acquired vaginal stenosis ${ }^{3}$. Since vaginal agenesis was described in 1927 by Realdus Colombus, attempts have been made by numerous surgeons to describe surgical procedures that could be used in order to create a new vagina for such patients. Indeed, the historical developments of these procedures have been aptly traced ${ }^{3,4}$. However, since 1938," Mcindoe - Read vaginoplasty ${ }^{5}$ has become quite popular and many workers have reported their experience with this procedure ${ }^{6,7}$ More recently, Arthur Williams ${ }^{8}$ described vulvo-vaginoplasty for his patients in order to create a pouch solely for coitus. Experiences of other workers in the tropics and developing world on vaginoplasty for acquired gynaetresia are hard to come by in the English Literature.

In separate earlier reports, Adewunmi in $1984^{3}$ and Ozumba in $1992^{6}$ have published related reviews on acquired gynaetresia in the sub-region. This paper highlights our experience in the surgical management of acquired gynaetresia at the University College Hospital, Ibadan and treatment outcume within the period.

\section{Materials and Methods}

Case records of patients with acquired gynaetresia managed between January 1994 and December 1998 in the Department of Obstetrics and Gynaecology, University College Hospital, Ibadan were retrieved. A total of 59 cases of acquired gynaetresia were managed during the period. Of these, 52 case records were retrieved that contained enough information for analysis. Intormation extracted from the records includes the socio-demographic characteristics of the patients, treatment methods and the results of treatment.

Correspondence: Dr. M.A. Okunlola, Department of Obstetrics and Gynaecology, University College Hospital, Ibadan, Nigeria. 


\section{Results}

In the period under review, 59 cases of acquired gynaetresia were managed. During the same period there were 11,346 gynaecological admissions, giving a frequency of 5.2/1000. The ages ranged from 5-54 years (Table 1). Over half of the patients were in the age range of 20-40 years, $44.2 \%$ being aged $21-30$ years. Two of the patients were children below 10 years of age. One presented with vaginal discharge and the other with dysuria. Majority of the women were nulliparous $(57.7 \%)$, or of low parity. Only one patient with parity greater than 4 presented with acquired gynaetresia.

The commonest cause of acquired gynaetresia in this series was chemical vaginitis, accounting for 43 of the 53 cases or

\section{Table 1}

Age Distribution of Acquired Gynaetresia in Ibadan

\begin{tabular}{|c|c|c|}
\hline Age (years) & No. of Cases & Percentage \\
\hline$<10$ & 2 & 3.9 \\
$11-20$ & 5 & 9.6 \\
$21-30$ & 23 & 44.2 \\
$31-40$ & 14 & 26.9 \\
41 and above & 8 & 15.4 \\
\hline
\end{tabular}

\section{Table 2}

Aetiology of Acquired Gynaetresia

\begin{tabular}{|l|c|c|}
\hline \multicolumn{1}{|c|}{ Aetiology } & $\begin{array}{c}\text { No. of } \\
\text { Cases }\end{array}$ & $\%$ \\
\hline Chemical Vaginitis & 43 & 82.7 \\
Birth Injuries & 4 & 7.7 \\
Circumcision & 3 & 5.7 \\
Post-operative & & \\
$\quad$ Injuries & 1 & 1.92 \\
Pelvic Infection & 1 & 1.92 \\
\hline
\end{tabular}

The therapeutic procedures done on the patients are shown in Table 5. Twenty-seven patients had vaginoplasty with post-operative vaginal dilatation and Mcindoe's operation (division of the stenosed vaginal wall and skin grafting on a mould) was performed as a 2-stage procedure in 13 patients. Williams' operation (dissection and pedicle graft from the labia minora) was dont in one patient. One patient had drainage of haematocolpos, followed later by separation of vaginal adhesions and dilatation of the vagina.

Among the 52 treated patients, post-operative complications were recorded in eleven and most of these had more than one complication. The full range of
$82.7 \%$ (Table 2). This resulted from vaginal insertion of chemical pessaries (local herbs) for the treatment of amenorrhoea in 20 patients, for the treatment of infertility in 13 patients and to procure abortion in 5 of the patients (Table 3). Post-circumcision fibrosis was seen in 3 patients while one case followed vaginal repair of uterovaginal prolapse.

The commonest presenting complaint was coital difficulty in 18 of the patients (Table 4), closely followed by amenorrhoea and infertility. The predominant clinical finding on examination was vaginal narrowing and shortening at various levels. There was complete occlusion of the vagina in 5 patients, labial agglutination in 3 patients and haematocolpos in one patient.

\section{Table 3}

Reason for Vaginal Insertion of Local Pessaries

\begin{tabular}{|l|c|c|}
\hline \multicolumn{1}{|c|}{ Aetiology } & $\begin{array}{c}\text { No. of } \\
\text { Cases }\end{array}$ & $\%$ \\
\hline Treatment of Amenorrhoea & 20 & 46.5 \\
Treatment of Infertility & 13 & 30.2 \\
To Procure Abortion & 5 & 11.6 \\
Treatment of Vaginal & & \\
Discharge & 2 & 4.7 \\
To Improve Coital Performance & 1 & 2.3 \\
Reasons Unknown & 2 & 4.7 \\
\hline
\end{tabular}

\section{Table 4}

Symptomatology of Acquired Gynaetresia in Ibadan

\begin{tabular}{|l|c|c|}
\hline \multicolumn{1}{|c|}{ Symptoms } & $\begin{array}{c}\text { No. of } \\
\text { Cases }\end{array}$ & $\%$ \\
\hline Dyspareunia/Apareunia & 18 & 34.7 \\
Amenorrhoea & 14 & 27 \\
Infertility & 10 & 19.6 \\
Dysmenorrhoea & 7 & 13.5 \\
Vaginal Discharge & 2 & 3.9 \\
Dysuria & 1 & 1.9 \\
\hline
\end{tabular}

complications noted are recorded in Table 6 . Thirty-nine of the 52 patients returned for the first follow-up visit, 18 for the second visit and only 5 for a $3^{\text {rd }}$ follow-up visit. Assessment of success of treatment as regards capacity of the vagina and absence of coital discomfort was encouraging by the $1^{\text {st }}$ follow up visit, majority of the patients attesting to this. Pregnancy was recorded in 3 of the patients that had vaginoplasty (single or double-stage) during the follow-up period. The three patients were successfully delivered at the University College Hospital, Ibadan, at term, all by elective lower segment caesarean section. Three patients had recurrence of severe vaginal stenosis. 


\section{Table 5}

Treatment Modalities in the Patients

\begin{tabular}{|l|c|c|}
\hline \multicolumn{1}{|c|}{ Treatment } & $\begin{array}{c}\text { No. of } \\
\text { Patients }\end{array}$ & $\%$ \\
\hline $\begin{array}{l}\text { Dilatation of the Vagina only } \\
\text { Vaginoplasty + dilatation of the }\end{array}$ & 7 & 13.5 \\
vagina & 27 & 52.0 \\
Two stage vaginoplasty & 13 & 25.0 \\
(Mcindoe's operation) & 3 & 5.8 \\
Separation of vulva adhesion \\
Williams' vulvo-vaginoplasty & 1 & 1.9 \\
$\begin{array}{l}\text { Drainage of haematotocolpos } \\
\text { and vaginoplasty }\end{array}$ & 1 & 1.9 \\
\hline
\end{tabular}

\section{Discussion}

Acquired gynaetresia constitutes a significant proportion of cases seen in our gynaecological clinics as in other centres in Nigeria - about 5.2/1000 admissions in this study. This condition is a most serious_one since it militates against satisfactory sexual life of the couple, thereby introducing stress into the marital relationship. Where it results in infertility, it might ultimately lead to separation or divorce since a childless marriage is perceived as a failed marriage in most Nigerian communities 6.9 .10

Chemical vaginitis from insertion of local herbs was found to be the commonest aetiology of gynaetresia in this study. This is in contrast to the findings in Eastern Nigeria 6 , where female circumcision was the cause in $76 \%$ of 76 cases of acquired gynaetresia reported. In both Eastern and Western Nigeria, it is the widely accepted belief thăt circumcision attenuates promiscuity in the female. While the procedure is still widely practised in Western Nigeria, it is usually limited to the removal of the clitoris and trimming of the labia minora, whereas among the Igbo of Eastern Nigeria the prevalent method of circumcision is removal of the clitoris and entire labia minora ${ }^{6,12}$. This may be responsible for the high incidence of gynaetresia following circumcision in that area.

The commonest presenting symptom was coital difficulty in 34.7 of patients. It was followed by amenorrhoea and infertility. This is similar to the finding of Adelusi and Adewunmi $^{4}$ in Ibadan but differs from the finding of Ozumba ${ }^{6}$ where the urinary symptoms of dysuria and retention were predominant. Since female circumcision was the most predominant predisposing factor for the development of gynaetresia in the latter study, this often caused direct urethral injury, urethral intercourse was frequent in these patients as a result of apareunia or dyspareunia and this frequently led to recurrent urinary tract infection and consequently dysuria. Also, a large haematocolpos may occasionally distort the bladder base and urethra subsequently leading to difficulty in initiating micturition. Only one of the patients in this study presented with urinary symptoms.

\section{Table 6}

Post Operative Complications after Vaginoplasty

\begin{tabular}{|l|c|}
\hline \multicolumn{1}{|c|}{ Complication } & No. of Cases \\
\hline Genital Sepsis & 5 \\
Haemorrhage & 3 \\
Urinary Tract Infection & 3 \\
Vulva Pain / discomfort & 2 \\
Expulsion of mould & 2 \\
\hline
\end{tabular}

The treatment offered to the patients in this series depended on the age of the patient, her future reproductive plans and the severity of the lesion. Vaginoplasty for acquired gynaetresia is more difficulty than that for correction of congenital defects because of dense fibrosis and distortion of anatomic relationships ${ }^{6,13}$. Occasionally, the question of whether any surgical treatment should be attempted is considered. For instance, it may not be worthwhile attempting to reopen a stenosed vagina at or after menopause. Nót only does post-menopausal atrophy make the stenosis worse, but also infrequent sexual intercourse after the reconstruction may fail to keep the new vagina open. Where there is minimal stenosis, all that may be necessary is dilatation with graded vaginal glass dilators till the largest size is inserted easily without pain ${ }^{4}$. Seven of our patients had no major operative treatment other than vaginal dilatation with glass dilators while other patients had dissection of the stenosed vaginal wall and reconstruction, followed by regular dilatation of the vagina twice daily from the $10^{\text {th }}$ day to 3 to 6 months. Regular sexual intercourse was encouraged in them as soon as they were weaned off the glass dilators. This is the recommended treatment in cases where there is occlusion of a considerable portion of the vagina $a^{3,4}$. Satisfactory result as evidenced by the capacity of the vagina recorded in many of these patients.

Drainage of haemotocolpos and later dissection and reconstruction of the vagina followed by regular vaginal dilatation was performed in one patient who had a large haematocolpos. Prophylactic antibiotics were given. The interval between drainage and vaginoplasty ( 2 weeks) is essential in order to reduce the chances of infection to which they are highly prone and to achieve better operative result ${ }^{1.3}$. 
Major vaginoplastly with skin grafting done as à two-stage procedure as described by Mcindoe and Bannister ${ }^{5}$ is useful in cases of complete occlusion of a significant portion of the vagina ${ }^{6}$. Nine of the 13 patients undergoing this procedure had satisfactory results. An earlier review in Ibadan $^{13}$ recorded 10 successful pregnancies following vaginoplasty in 28 patients, but only three of the patients in this group got pregnant.

The probiem of acquired gynaetresia is considerable and is of significant reproductive health importance. This problem can only be effectively tackled by community-based education where the ugly results of insertion of chemicals into the vagina and the dangers of female circumcision will be highlighted. The consequences of patronizing untrained local health practitioners and midwifery personnel should be brought home to the general populace. It is believed that this will significantly reduced the incidence of acquired gynaetresia in Nigeria.

\section{References}

1. Lawson JB. Acquired Gynaetresia. In Lawson JB, Stewart, DB. (eds). Obstetrics and Gynaecology in the Tropics \& Developing Countries, 1st Edition. London, Edward Arnold Ltd. 1967

2. Unuigbe JA, Ojobo S, Oronsanye AU. The challenges of vaginal atresia and stenosis: the Nigerian experience. Int J Gynecol Obstet. 1984; 22: 1-4.

3. Adewunimi OA. Vaginoplasty in the University College Hospital, Ibadan. East Afr Med J. 1984; 61: 169-174.

4. Whitley JM, Parrot MH, Rowland W. Split-thickness skin graft technique in the correction of congenital or acquired vaginal atresia. Am J Obstet Gynecol. 1964; 89: $377-389$

5. Mclndoe AH, Bannister JB. An operation for the cure of congenital absence of the vagina. J Obstet Gynaecol Br Emp. 1938; 45: 490-499.

6. Ozumba BC. Acquired gynaetresia in Eastern Nigeria. Int J Gynecol Obstet 1992; 37: 105-109.

7. Salvatore-Ludovici CA. Vàginal agenesis: analysis of 90 cases. Acta Obstet Gynaecol Scand. 1978, 57: 8996.

8. Williams EA. Congenital absence of the vagina: a simple operation for its relief. $J$ Obstet Gynaecol $\mathrm{Br}$ Commwlth. 1967; 71: 511-524.

9. Mustafa AZ. Female circumcision in the Sudan. $J$ Obstet Gynaecol Br Commwlth. 1966; 73: 302-308.
10. Adelusi A, Onifade A, Akande EO. Acquired gynaetresia obstructing labour. Nig Mea .I. 1980; 8: 271-273.

11. Egwuatu VE, Agugua NEN. Complications of female circumcision in Nigerian Igbos. Br J Obstet Gynaecol. 1988; 88: 1090-1093.

12. Megafu U. Surgical causes and management of female infertility in Nigeria. Int Surg. 1988; 73: 144.

13. Adelusi B, Onifade A, Akande EO, Ladipo OA. Obstetric performance after vaginoplasty. Nig Med J 1976; 5 : 356-358. 